\title{
Thoracoscopic treatment of benign esophageal tumors
}

\author{
Čestmír Neoral', René Aujeskýn, Jozef Škarda², Radek Vrba ${ }^{1}$, Josef Chudáček ${ }^{1}$, Tomáš Bohanes ${ }^{1}$, Katherine Vomáčková ${ }^{1}$ \\ ${ }_{1}^{1} 1^{\text {st }}$ Department of Surgery, Palacký University, Teaching Hospital, Olomouc, Czech Republic \\ 2Department of Pathology, Palacký University, Teaching Hospital, Olomouc, Czech Republic
}

Videosurgery Miniinv 2012; 7 (4): 294-298

DOI: $10.5114 /$ wiitm.2011.30817

\begin{abstract}
Introduction: Gastrointestinal stromal tumors are among the most frequent mesenchymal tumors of the gastrointestinal tract; the incidence of these tumors in the esophagus is less than 5\%. Prognosis depends on localization, size, mitotic activity and possible invasion of surrounding structures. Minimally invasive surgery may be maximally utilized for removal of these tumors from the esophageal wall. This operation is usually performed thoracoscopically or laparoscopically and using the "rendez-vous" method - with endoscopic navigation.

Aim: To evaluate a set of patients with benign tumor of the esophagus who were operated on at the First Department of Surgery from 2006 to 2011.

Material and methods: In the years 2006-2011 a total of 11 patients with benign tumors of the esophagus underwent operation.

Results: Of the 11 patients with esophageal tumor, 5 were diagnosed with gastrointestinal stromal tumor, 5 with leiomyoma and in one patient the lesion was described as heterotopy of the pancreas. We used the minimally invasive rendez-vous method with endoscopic navigation in 9 cases. All patients healed primarily and were released from hospital on the $4^{\text {th }} 7^{\text {th }}$ day. These patients are being followed up as outpatients and recurrence of the tumor has not been observed in any of them.

Conclusions: Minimally invasive treatment of benign tumors of the esophageal wall is considered to the method of choice. Due to possible complications and the need for subsequent therapy in some patients, these procedures should be centralized to departments with experience in esophageal, thoracic and minimally invasive surgery.
\end{abstract}

Key words: esophagus, esophageal tumor, thoracoscopy, benign tumor.

\section{Introduction}

Benign esophageal tumors are not very common. The great majority are mesenchymal tumors. In the past, their classification underwent significant changes especially due to the expansion of immunohistochemical examination methods.

Gastrointestinal stromal tumors (GIST) are among the most frequent mesenchymal tumors of the gastrointestinal tract. A summary of studies quotes the greatest incidence of these tumors to be in the stom- ach $(60-70 \%)$, followed by the small intestine (20-25\%), large intestine (5\%) and the least frequent localization is the esophagus $(<5 \%)$ [1-3]. The current definition of GIST (gastrointestinal stromal tumor) is, in its least controversial form, quite broad. It is a group of non-epithelial tumors of the digestive tract formed by spindle and/or epithelioid cells, which most authors assume to originate in the progenitor cell, which differentiates towards interstitial cells of Cajal. Currently the expression of KIT protein is no longer a necessary condition for GIST diagnosis and 
most authors do not consider the absence of c-kit (or PDGFRA) gene mutation to be an exclusion criterion when there is corresponding morphology. In such tumors, GIST becomes a diagnosis of exclusion, after other mesenchymal lesions of the digestive tract have been excluded [4-7]. Prognosis of these tumors depends on:

- localization (for example, tumors located in the stomach have a better prognosis than in the small intestine, or even outside the gastrointestinal tract),

- size,

- mitotic activity and possible invasion of surrounding structures,

- leiomyoma - benign tumor - from smooth muscles,

- granular cell tumors (Abrikossoff's tumor) - neural tumors, benign character,

- lipoma, fibroma, fibrolipoma - are rare in this localization.

To determine further treatment in cases where surgical extirpation was not performed, and for prognosis of the disease, histological and immunohistochemical analysis are necessary. Most tumors grow submucosally and do not disturb the integrity of the mucosa. Minimally invasive surgery may be maximally utilized for removal of the tumor from the esophageal wall. This operation is usually performed using the "rendez-vous" method - with endoscopic navigation. The choice of thoracoscopic or laparoscopic approach depends on localization of the lesion.

\section{Material and methods Diagnostics}

In addition to basic examination methods such as $X$-ray barium swallow, endoscopy and computed tomography $(\mathrm{CT})$, recently positron emission tomography (PET)-CT and endosonography of the esophagus (Figure 1) are being indicated in all patients. We emphasize the inappropriateness of endoscopic biopsy since it could result in disturbed mucosal tissue integrity and as such place the minimally invasive procedure of tumor extirpation from the muscle layer at risk.

\section{Indications for operation}

All patients are indicated for minimally invasive surgical treatment provided that the tumor is not gigantic in size, that the esophageal mucosa is not disturbed, and that there are no general contraindi- cations for the surgical procedure. It is open to discussion whether lesions smaller than $2 \mathrm{~cm}$ should be indicated for extirpation or whether the patients should only be monitored.

\section{Contraindications}

Contraindications for operation include overall poor condition of the patient. Patients planned for thoracoscopy are contraindicated for an intrathoracic procedure. In addition, a relative contraindication is gigantic parameters of the tumor, when a classical surgical procedure is clearly recommended.

\section{Operating equipment}

Thoracic trocars, endoscopic camera system: 0- or 30-degree thoracoscope, ultrasonographic scalpel, grasping forceps, dissecting laparoscopic forceps, endostapler, esophagogastroscope.

\section{Method description}

The thoracoscopic approach is based on lesion localization. Usually an approach from the lower part of the thoracic cavity is used $\left(6^{\text {th }}-8^{\text {th }}\right.$ intercostal space) above the diaphragm in the anterior, middle and posterior axillary line. One $10 \mathrm{~mm}$ entry for the camera and two $5 \mathrm{~mm}$ entries for grasper or for-

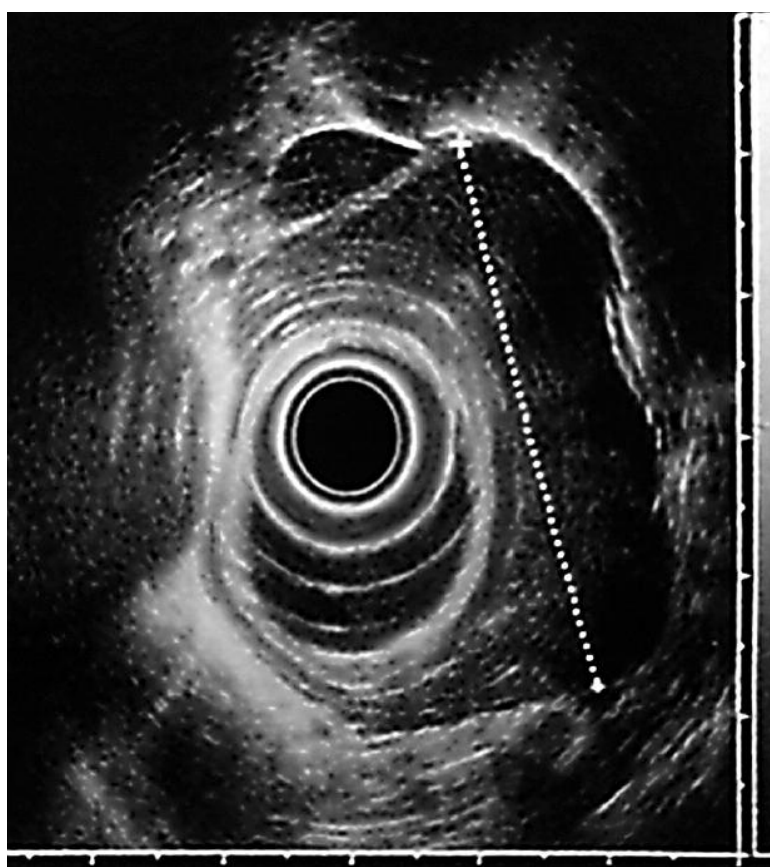

Figure 1. Endo-ultrasound image showing the tumor in the wall of the esophagus 


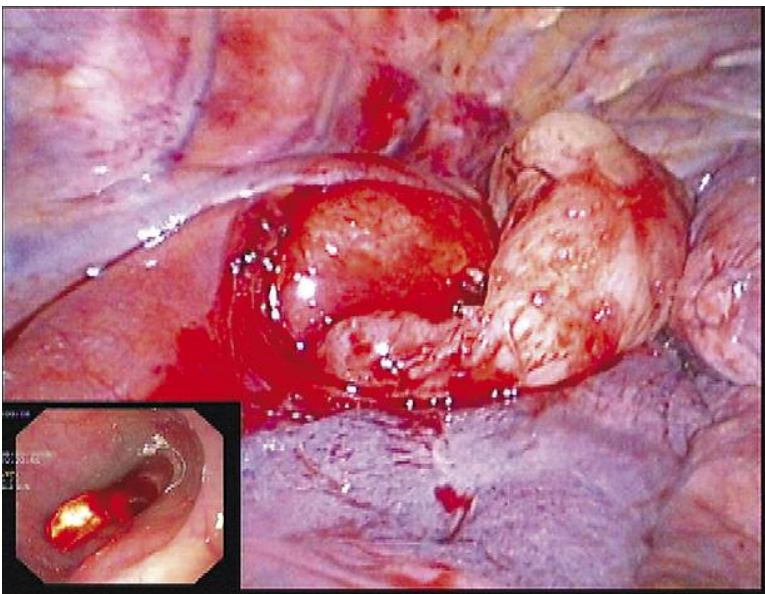

Figure 2. The dissected tumor with a prolapse of the mucosa through the opened esophageal muscle layer. Endoscopic view shows no injury to the esophageal mucosa

ceps or ultrasonographic scalpel are used. The endoscope is introduced and the rendez-vous method is used to verify the tumor in the esophageal wall. First sharp dissection is used in the muscle layer to approach the tumor, then using blunt preparation the tumor is extirpated from the esophageal wall without disturbance to the integrity of the mucosa, if possible (Figure 2). If the mucosa is disrupted, it is necessary to suture it, as well as the muscle layer, or in cases of a small defect in the muscular layer, it may be left without reconstruction. The integrity of the mucosa is monitored throughout the procedure endoscopically. Finally a chest tube is introduced and the operative field is irrigated.

For the laparoscopic transhiatal approach: the ports are introduced similarly as in operations of hiatal hernias, only they are positioned slightly higher. Usually two $10 \mathrm{~mm}$ and two $5 \mathrm{~mm}$ ports are used. The procedure begins with dissection of the right and left crura. Then, if necessary, the transition from thoracic to abdominal esophagus is dissected. With the help of endoscopy, the bulge in the esophageal wall is localized and the tumor is dissected, usually bluntly so as to prevent disruption of the mucosa. After extirpation, the size of the defect in the muscular layer is evaluated and in cases where there is a risk of future pseudodiverticula development, it is appropriate to suture the muscular layer. In the area immediately above the cardia, it is possible to cover the defect by performing a Dorr semifundoplication.

\section{Results}

In the years 2006-2011 a total of 11 patients with benign tumors of the esophagus underwent operation. Subsequently 5 of these patients were diagnosed with gastrointestinal stromal tumor of the esophagus, 5 with leiomyoma of the esophagus and in one patient the lesion was described as heterotopy of the pancreas. The set included 10 males and $1 \mathrm{fe}$ male. Tumor localization was 7 times in the region of the thoracic esophagus and 4 times in the region of the abdominal esophagus or at the transition between the thoracic and abdominal portions of the esophagus (Table I). Preoperative examination by endoscopy, CT and endoluminal sonography always confirmed the tumor bulging under an intact mucosa growing in the esophageal wall in the muscular layer, without invasion of surrounding structures. One case consisted of an enormous pendulous tumor connected to the esophageal wall by a $1.5 \mathrm{~cm}$ wide stalk. The tumor filled the lumen of the esophagus at a length of approximately $12 \mathrm{~cm}$. In all cases surgical removal of the tumor was indicated. We used the minimally invasive rendez-vous method in 9 cases, where the surgical procedure was navigated endoscopically. In 6 cases the tumor was removed videothoracoscopically. In 1 case of a large tumor, the VATS technique was used and the tumor was removed from the esophagus through the opening used for excision of its stalk. The tumor was removed via a transhiatal laparoscopic approach in 4 cases when the tumor was localized in the distal part of the esophagus or at the transition between the thoracic and abdominal portions of the esophagus. All patients healed per primam and on the $4^{\text {th }}-7^{\text {th }}$ postoperative day were released from hospital. These patients are being followed up as outpatients and recurrence of the tumor has not been observed in any of them.

\section{Discussion}

Benign esophageal tumors are not very frequent; however, their occurrence necessitates surgical treatment. Tumors located in the esophagus are different from tumors located in other parts of the digestive tract. A common surgical resection with primary endto-end anastomosis is not possible in this localization and the surgical resection requires a more extensive, usually a two-cavity, procedure. Obtaining valid con- 
Table I. Description of the patient set

\begin{tabular}{|c|c|c|c|c|c|}
\hline Name & Sex & $\begin{array}{c}\text { Age } \\
\text { [years] }\end{array}$ & $\begin{array}{l}\text { Localization by endoscopy } \\
\text { (distance from the incisors) }[\mathrm{cm}]\end{array}$ & $\begin{array}{c}\text { Type of operation } \\
\text { always assisting endoscopy }\end{array}$ & Histology \\
\hline D.J. & M & 51 & 38 & $\begin{array}{l}\text { Videolaparoscopic } \\
\text { transhiatal extirpation }\end{array}$ & $\begin{array}{l}\text { Spindle cells, SMA+, Desmin+, } \\
\text { S100 a CD34-, CD117-, } \\
\text { leiomyoma }\end{array}$ \\
\hline D.P. & M & 63 & 42 & LSK resection of the tumor & Heterotopy of the pancreas \\
\hline K.L. & M & 46 & 26 & $\begin{array}{c}\text { Right videothoracoscopic } \\
\text { extirpation }\end{array}$ & $\begin{array}{c}\text { Spindle cells, SMA+, C- kit+, } \\
\text { GST }\end{array}$ \\
\hline B.M. & M & 60 & 28 & Right TS extirpation & $\begin{array}{l}\text { Spindle cells, SMA+, } \\
\text { S100-, Desmin+, C-kit-, } \\
\text { leiomyoma }\end{array}$ \\
\hline C.L & M & 75 & 37 & $\begin{array}{l}\text { LSK transhiatal extirpation } \\
\text { fundoplication }\end{array}$ & $\begin{array}{l}\text { Spindle cells, SMA+, } \\
\text { desmin-, S100-, CD117+, } \\
\text { GIST }\end{array}$ \\
\hline H.S. & M & 55 & 25 & Right TS extirpation & $\begin{array}{l}\text { SMA+, Desmin+, S100 a CD34-, } \\
\text { CD 117-, leiomyoma }\end{array}$ \\
\hline V.J. & M & 43 & $31-36$ & Right TS extirpation & $\begin{array}{c}\text { SMA+, Desmin+, S100 a CD34-, } \\
\text { CD 117-, leiomyoma }\end{array}$ \\
\hline N.B. & $\mathrm{F}$ & 68 & 34 & Right TS extirpation & $\begin{array}{c}\text { SMA+, Desmin-, S100 a CD34-, } \\
\text { CD 117+, GIST }\end{array}$ \\
\hline M.F. & M & 36 & 23 & Right TS extirpation & $\begin{array}{l}\text { Spindle cells, SMA+, Desmin-, } \\
\text { S100-, CD117+, GIST }\end{array}$ \\
\hline P.J. & M & 34 & 39 & $\begin{array}{l}\text { LSK, laparotomy, extirpation, } \\
\text { fundoplication }\end{array}$ & $\begin{array}{l}\text { SMA+, Desmin+, } \\
\text { S100 a CD34-, CD 117-, } \\
\text { leiomyoma? }\end{array}$ \\
\hline Š.M. & M & 72 & 24 & $\begin{array}{l}\text { Extirpation of the esophagus } \\
\text { transthoracic approach }\end{array}$ & $\begin{array}{c}\text { SMA-, desmin-, S100-, } \\
\text { GIST? }\end{array}$ \\
\hline
\end{tabular}

firmation of the diagnosis preoperatively is already problematic and would practically exclude the abovedescribed procedure, which requires integrity of the mucosa and consists of extirpation of the tumor from the esophageal wall. Definitive diagnosis is established by immunohistochemical examination. In the case of GIST, mutation analysis may predict the need, as well as success, of imatinib mesylate therapy.

\section{Conclusions}

Minimally invasive treatment of benign tumors of the esophageal wall is considered to the method of choice. In cases of uncomplicated extirpation, the procedure is almost treacherously simple. However, due to the location, any complication significantly endangers the fate of the surgical procedure and therefore the patient. In cases where there is greater injury to the esophageal wall, the procedure may become very dramatic and in cases of greater complications it is not safe to continue the procedure minimally invasively and it is necessary to convert to an open procedure. Not only for these reasons, but also due to patients requiring subsequent therapy, we unequivocally recommend centralizing these procedures to departments with experience in esophageal, thoracic and minimally invasive surgery.

\section{References}

1. Miettien M, Sarlomo-Rikala M, Lasota J. Gastrointestinal stromal tumors: recent advances in understanding of thein biology. Hum Pathol 1999; 30: 1213-20.

2. Miettien M, Lasota J. Gastrointestinal stromal tumors - definition, clinical, histological, immunohistochemical and molecular genetic features and differential diagnosis. Virchows Arch 2001; 438: 1-12. 
3. Sákra L, Šiller J, Vyhnálek P, Hácová M. Surgical treatment of gastrin and small bowel gastrointestinal stromal tumors. Videosurgery Miniinv 2011; 6: 138-43.

4. Mechtersheimer G, Egerer G, Hensel M, et al. Gastrointestinal stromal tumors and their response to treatment with tyroxine dinase inhibitor imatinib. Virchows Arch 2004; 444: 108-18.

5. Hornick JL, Fletcher CDM. The significance of KIT (CD117) in gastrointestinal stromal tumors. Int I Surg Pathol 2004; 12: 93-7.

6. Dei Tos AP. The reappraisal of gastrointestinal stromal tumors: from Stout to the KIT revolution. Virchows Arch 2003; 442 421-8.

7. Rosai J. GIST: an update. Int J Surg Pathol 2003; 11: 177-86.

Received: 16.03.2012, Revised: 6.05.2012, Accepted: 29.05.2012. 